Keynote Presentations

K01 - OPENING KEYNOTE LECTURE - 2019

ISSTDR PRESTIGIOUS LECTURE: BACTERIAL STI VACCINES - ETERNAL DREAM OR FUTURE REALITY?

Sunday, July 14, 2019 6:30 PM - 7:30 PM

\section{K01.1 BACTERIAL STI VACCINES - ETERNAL DREAM OR FUTURE REALITY?}

Rino Rappuoli*. GSK Vaccines, Siena, Italy

10.1136/sextrans-2019-sti.1

Vaccination has been the most effective medical intervention in the history of mankind. Infectious diseases that used to kill or cause disability in millions of people annually such as diphtheria, tetanus, smallpox, polio, measles, mumps, and rubella were conquered during the last century with the first wave of vaccines. The second wave of vaccination started during the 1980s and consisted of vaccines that were made possible by the new technologies such as recombinant DNA, conjugation, genomics, that allowed the development of vaccines against Hepatitis B, papillomavirus, Haemophilus influenzae, pneumococcus, and meningococcus. Thanks to the advances in understanding of the structure of the antigens and their epitopes and how they interact with the human immune system we are now entering the third wave of vaccine development, characterized by optimal design antigens, adjuvants and delivery systems. This new phase is expected to tackle diseases such as tuberculosis, malaria, and HIV and STIs that have, so far, been refractory to vaccine development.

\section{K02 - CLOSING KEYNOTE LECTURE - MAKING SCIENCE WORK TO DELIVER EFFECTIVE PROGRAMMES AT SCALE}

Wednesday, July 17, 2019 3:45 PM - 4:45 PM

\section{K02.1 MAKING SCIENCE WORK TO DELIVER EFFECTIVE PROGRAMMES AT SCALE}

Charlotte Watts*. 'London School of Hygiene and Tropical Medicine, London, UK; ${ }^{2}$ UK Department of International Development (DFID), London, UK
Plenary Presentations

D01 - DEBATE - AMONG MEN WHO HAVE SEX WITH MEN, PHARYNGEAL INFECTION CONTRIBUTES MORE TO POPULATION LEVELS OF GONORRHEA TRANSMISSION THAN URETHRAL INFECTION, RECTAL INFECTION, OR BOTH?

\author{
Wednesday, July 17, 2019 \\ 9:25 AM - 10:15 AM
}

\section{D01.1 AMONG MEN WHO HAVE SEX WITH MEN, PHARYNGEAL INFECTION CONTRIBUTES MORE TO POPULATION LEVELS OF GONORRHEA TRANSMISSION THAN URETHRAL INFECTION, RECTAL INFECTION, OR BOTH (FOR THE MOTION)}

Christopher Fairley ${ }^{*}$. Alfred Health, Melbourne Sexual Health Centre, Carlton, Australia

10.1136/sextrans-2019-sti.2

At first glance, it seems entirely reasonable that the penis is the key transmitting organ- it secrets large organism load and is inserted into mouth and anus. But ask yourself- how many men who one has sex with have gonorrhoea in their penis at the time? Is it enough to generate an incidence of about $20 \%$ in the throat and anus per year? The penis develops symptoms within days, has an incidence of only $5-10 \%$ per year so only 1 in 200 men at any one time are infectious. To generate a throat incidence of $20 \%$ would require about 100 partners a year assuming a high per partner transmission efficiency of $50 \%$. However at any point in time about $5-10 \%$ of men have throat gonorrhoea; most kiss and exchange saliva. To generate a $20 \%$ incidence in the throat would require 2 partners per year (50\% transmission). So why have we not considered this route of transmission seriously before? Some suggestions; culture was very insensitive at the throat and suggested infection was rare, kissing is highly correlated with other risks, some countries have longer duration urethral gonorrhoea from poor access to treatment and in these situations the penis does play a major role, and kissing has not been measured virtually at all until now. So what then is the evidence for kissing (and saliva) playing a role in transmission? Saliva is often culture positive when a throat is positive, people kiss often, kissing independently predicts the presence of throat gonorrhoea, saliva use during anal sex predicts anal gonorrhoea, positivity in partner studies don't fit just penile transmission, and recently outbreak of throat gonorrhoea could only be explained by kissing. You make your minds up. Is it time to re think gonorrhoea transmission with an open mind(or mouth).

Disclosure No significant relationships. 